\title{
String Theory, Non-Empirical Theory Assessment, and the Context of Pursuit
}

\author{
Frank Cabrera
}

\begin{abstract}
In this paper, I offer an analysis of the radical disagreement over the adequacy of string theory. The prominence of string theory despite its notorious lack of empirical support is sometimes explained as a troubling case of science gone awry, driven largely by sociological mechanisms such as groupthink (e.g. Smolin 2006). Others, such as Dawid (2013), explain the controversy by positing a methodological revolution of sorts, according to which string theorists have quietly turned to nonempirical methods of theory assessment given the technological inability to directly test the theory. The appropriate response, according to Dawid, is to acknowledge this development and widen the canons of acceptable scientific methods. As I'll argue, however, the current situation in fundamental physics does not require either of these responses. Rather, as I'll suggest, much of the controversy stems from a failure to properly distinguish the "context of justification" from the "context of pursuit". Both those who accuse string theorists of betraying the scientific method and those who advocate an enlarged conception of scientific methodology objectionably conflate epistemic justification with judgements of pursuit-worthiness. Once we get clear about this distinction and about the different norms governing the two contexts, the current situation in fundamental physics becomes much less puzzling. After defending this diagnosis of the controversy, I'll show how the argument patterns that have been posited by Dawid as constituting an emergent methodological revolution in science are better off if reworked as arguments belonging to the context of pursuit.
\end{abstract}

\section{Address:}

Department of Philosophy

Kansas State University

1116 Mid Campus Dr North

201 Dickens Hall

Manhattan, KS 66506-0803

Email: fjcabrera@ksu.edu

Acknowledgments: I am grateful to Megan Fritts, as well as the anonymous reviewers at Synthese, for many helpful comments and suggestions.

Keywords: String theory; scientific method; explanation; context of justification; context of pursuit; Bayesianism. 


\section{Introduction}

On December 7-9, 2015 at the Ludwig Maximilian University of Munich in Germany, physicists, philosophers, and historians of science gathered at a workshop entitled "Why Trust a Theory? Reconsidering Scientific Methodology in Light of Modern Physics." As the name of the workshop suggests, recent developments in contemporary physics have, ostensibly, led to a crisis in our collective understanding of good scientific method. In particular, fundamental physics has become increasingly divorced from experimental testing, and yet, physicists working in these areas continue to trust, maintain, work on, etc. theories for which there is little to no direct empirical evidence. The physical theory that has taken center stage in this controversy is, of course, the research program that goes by the name of "string theory." This mismatch between our traditional understanding of acceptable scientific methodology, one according to which science must be answerable to empirical reality, and the current situation in fundamental physics has provoked two general responses among philosophers, physicists, and other commentators.

On the one hand, we might insist that fundamental physics be reformed to conform to the canons of good scientific reasoning. This could involve several more specific approaches. For instance, we might insist that a greater emphasis be placed on the derivation of empirically accessible consequences of present theories, rather than further theoretical innovation. If that is not possible, say, because of insurmountable technological problems, then we might urge physicists to develop different theories that have the potential to be experimentally probed. On the other hand, we might think that it is our understanding of scientific method that ought to be reformed. If the best working fundamental physicists uphold theories for reasons that do not directly depend upon experimental testing or direct observation, then perhaps we ought to examine in detail what sorts of methods are being employed and expand our notion of acceptable scientific reasoning accordingly. Perhaps then these recent developments demand a reevaluation of proper scientific method. 
As I'll argue in this paper, however, the current situation in fundamental physics does not require either of these responses. The prominence of string theory suggests neither that scientists working on the theory have abandoned the scientific method in order to engage in unempirical, metaphysical speculation, nor that science is undergoing a methodological revolution. Rather, as I'll suggest, much of the controversy among philosophers and physicists over the scientific status of string theory stems from a failure to properly distinguish the "context of justification" from the "context of pursuit". Indeed, as I'll show, both those who accuse string theorists of betraying the scientific method and those that advocate an enlarged conception of scientific methodology objectionably conflate epistemic justification with judgements of pursuit-worthiness. As I'll argue, once we make this distinction and get clear about the different norms that govern each context, the current situation in fundamental physics with respect to string theory becomes much less puzzling. After articulating and defending this diagnosis of the controversy, I'll show how the argument patterns that have been posited by Dawid (2013) as constituting an emergent methodological revolution in science are better off if reworked as arguments belonging to the context of pursuit.

\section{String Theory and the Promise of Unification}

The foundational idea of string theory is that we should think of the fundamental constituents of matter as extended one-dimensional objects called "strings", rather than the more familiar pointlike entities from traditional particle physics. According to string theory, there exist strings of different types, e.g. "open" or "closed", depending of the version of string theory in question, which oscillate in certain ways, and these vibrations give rise to different particles that we observe. In particular, the intrinsic properties of particles, such as their masses and charges, can be understood in terms of the vibrations of these one-dimensional objects. In addition, for string theory to be consistent with particle physics, it must be formulated in a spacetime of ten dimensions. Since we only observe four dimensions, those extra dimensions must be "compactified", rolled up in on themselves in complex 
configurations so as to be hidden from plain view. It has been discovered that the various versions of string theory that had been developed are related in important ways-by so-called "duality relations" - to a more general theory known as "M-theory" (Witten 1995), which posits an ontology of two-dimensional membranes rather than one-dimensional strings. Even though there are different versions of string theory and now M-theory, as Dawid (2013: 15) notes, "duality implies that the five types of superstring theories and M-theory only represent different formulations of one single actual theory." With this in mind, henceforth, I will use the term "string theory" to refer broadly to both the earlier theories that posit one-dimensional strings along with their successor in the form of M-theory.

To understand the attraction of string theory, it is important to first note that unification has always been an important goal of natural science, ever since Thales of Miletus (624-546 B.C.E.) theorized that everything is water. Indeed, it is not inaccurate to think that " $[t]$ he evolution of fundamental physics can be construed as a series of unifications” (Dawid 2013: 9). One of Newton's key accomplishments was to bring together the superlunary and sublunary realms, showing, contra Aristotle, that celestial phenomena and terrestrial phenomena were both governed by the same gravitational force. Later, in the $19^{\text {th }}$ century, Maxwell brought together the previously distinct phenomena of electricity and magnetism in his unified theory of light. So too, among the many achievements of Einstein in 1905-his annus mirabilis — was the unification of classical mechanics and electrodynamics by way of the theory of special relativity.

One problem that remains, however, is the unification of all four known forces in fundamental physics: the gravitational force, the strong force, the weak force, and the electromagnetic force-what Jones (2008: 489) calls "the holy grail of physics". Some successes have been made in unifying some of these forces. For instance, Glashow, Sheldon, and Weinberg shared the Nobel prize in physics in 1979 for their contributions toward unifying the electromagnetic force with the weak force, which plays a central role in the phenomenon of radioactive decay. But attempts to integrate the gravitational 
force, described by the general theory of relativity, into the Standard Model of particle physics—which describes the weak, strong, and electromagnetic forces, and is ultimately grounded in quantum physics - have proved extraordinarily difficult. Such attempts at extending the Standard Model to cover gravity have led to calculations with ineliminable infinities, those that are "non-renormalizable", signaling that something has gone wrong (Isham 1981).

In this context, the allure of string theory is that it potentially offers in tandem, a consistent theory of quantum gravity, and a unification of all four fundamental forces. Originally, string theory was proposed as a theory only of the strong force, i.e. the force that holds together the sub-atomic particles that compose the nucleus of the atom. ${ }^{1}$ In its earliest phases-known then as "the dual resonance model" (Veneziano 1968)—string theory had some initial successes in explaining the strong force and unifying the myriad different types of hadrons (i.e. strongly-interacting particles, of which protons and neutrons are well-known examples) being created in particle accelerators. But ultimately string theory as a theory of hadrons failed and was eclipsed by the more familiar theory of quantum chromodynamics and the quark model of hadrons. However, in what Rickles (2014: 134) describes as “the most extraordinary case of 'theoretical exaptation' in the history of physics", string theory was soon discovered to have the potential to be the "grand unified theory", for which Einstein spent the last thirty years of his life attempting to discover (Scherk and Schwarz 1974).

In its more familiar guise as a universal theory of everything, comprehending all phenomena, string theory began to increase in prominence around 1984, with the publication of a paper by Green and Schwarz (1984) demonstrating how to tackle certain anomalies that had plagued the theory. As work on the theory continued, so too did the excitement with respect to its potential as a maximally unifying framework. As the physicist Brian Greene enthuses in his popular book, The Elegant Universe:

${ }^{1}$ See Rickles (2014) for a comprehensive history of the development of string theory. 
String theory has the potential to show that all of the wondrous happenings in the universe from the frantic dance of subatomic quarks to the stately waltz of orbiting binary stars; from the primordial fireball of the big bang to the majestic swirl of heavenly galaxies - are reflections of one, grand physical principle, one master equation (1999: 7).

If unification is a goal of science, then the excitement expressed by Greene and other supporters of string theory toward its prospects for unification are, one might think, entirely sensible.

\section{The Controversy over String Theory}

Despite the enthusiasm of Greene and other proponents, string theory has been subject to a wave ofmtrenchant and high-profile criticism over the last two decades (Woit 2006; Smolin 2006). The facts that are cited by critics are ones that even string theorists openly acknowledge. For one thing, there is no direct empirical evidence that strongly confirms that reality is actually described by string theory. There are possible observations that, in principle, could directly test string theory, but they require energy levels that exceed those reached in our particle accelerators by several orders of magnitude. And so, anything approaching a crucial experimental test of string theory is unfeasible for the foreseeable future. Thus, practically-speaking, the theory is untestable.

Second, string theory is incomplete in important ways. At present the various "free parameters" of the Standard Model, such as the masses, charges, and spin values of elementary particles, must be fixed by empirical observation. Still, there remains a hope that a deeper theory, such as a string theory, will entail these values in an elegant way from its core postulates, so that they do not need to be determined experimentally. Despite its initial promise, there is reason to believe that string theory cannot so determine these parameters, since our best understanding of the theory now is one according to which the theory consists of an "ensemble" or "landscape" of $10^{500}$ possible solutions, each one corresponding to a different configuration of the extra dimensions hidden from ordinary observation (Kachru et al. 2003). Currently, we do not know which solution corresponds to 
our universe, and even if we did, we would still not know why one solution is the true one rather than the others. Thus, key questions about the very structure of the theory remain unanswered. ${ }^{2}$

As I've mentioned, these facts are widely known and acknowledged by both proponents and critics of string theory, but opposite conclusions are drawn. Amid his passionate praise of the "astonishing insights into the nature of space, time, and matter" afforded by string theory, Greene readily recognizes that the theory is a "work in progress" and that "nothing is a substitute for definitive testable predictions" (1999: 18), clearly suggesting though that these deficiencies are no reason to abandon the theory. However, precisely because of these deficiencies, critics such as Lee Smolin (2006) argue that the popularity of string theory among physicists signals that something has gone severely wrong in discipline. Indeed, Smolin provocatively likens string theory to the much-maligned theory of intelligent design, writing that "each provides an untestable hypothesis that, if true, makes something improbable seem quite probable" (2006: 164), and moreover, claims that "those who believe the conjectures [of string theory] find themselves in a very different intellectual universe from those who insist on believing only what the actual evidence supports" (2006: 198).

\section{Two Responses to the Controversy: Groupthink vs. Methodological Revolution}

In a recent and important book entitled String Theory and Scientific Method (2013), which partly inspired the workshop that took place in Munich in December 2015, the physicist-turned-philosopher Richard Dawid attempts to explain the prominence of string theory in spite of the powerful criticism levelled against it. Regarding the datum that requires an explanation Dawid writes:

Given its unsatisfactory theoretical state and the lack of empirical confirmation, string theory clearly must be called an unconfirmed speculative hypothesis according to the canonical paradigm of theory assessment. This does not square well, however, with the theory's actual status in the field of high energy physics. String theory has attained a pivotal role in fundamental physics and has been treated as a well-established and authoritative theory for quite some time by the community of string theorists and by physicists in related fields. As we

\footnotetext{
${ }^{2}$ It should be noted that these problems, among others, e.g. the failure to observe supersymmetry in the Large Hadron Collider, have certainly lessened the dominance of string theory in recent years. Even so, the current and recent-past status of string theory remains worthy of philosophical reflection.
} 
have described above, large parts of fundamental physics are influenced by string theoretical analysis. The string community is one of the largest communities in all of theoretical physics and for many years has produced the majority of the field's top-cited papers. Moreover, many string theorists express a remarkably strong trust in their theory's viability. Though they certainly acknowledge their theory's theoretical incompleteness and the lack of empirical evidence for it as deplorable obstacles, most of them believe that the theoretical quality of string theory in itself justifies the claim that the theory constitutes an important step towards a deeper understanding of nature. (2013: 19)

This datum, suggests Dawid (2013: 20), can be regarded as a "test case" for a given "philosophical perspective", whereupon if "the suggested perspective is capable of providing a convincing explanation of the dispute, it may be taken to be supported by this explanatory success."

It is thus worth noting that the general epistemological framework in which Dawid's argument is situated is that of "Inference to the Best Explanation" (IBE). Although IBE is primarily regarded as a general theory of scientific inference (Lipton 2004; Psillos 2002), recently it has been argued that IBE is an indispensable philosophical tool as well. ${ }^{3}$ Throughout, like Dawid, I will assume that IBE is a legitimate way in which to defend a philosophical position.

Of the two possible responses that one might have to the current state of fundamental physics laid out in the introduction, Smolin (2006: 167) is a staunch advocate of the first. In his view, we ought to further develop fundamental theories that can be definitively tested with current technology, such as his own theory of "cosmological natural selection." Since working physicists are surely familiar with the canons of scientific reasoning, some explanation of their failure to develop alternative theories that are testable is required. The explanation favored by Smolin (2006: 284-8) for the failure to develop alternatives to string theory is one in terms of sociological and psychological mechanisms, such as groupthink, the desire to further one's career, or the desire to increase one's social standing in the discipline. Similar sorts of explanations are endorsed by Woit (2006: 9, 206). For convenience, let's refer to these sorts of explanations of the controversy as the "Sociological Thesis".

\footnotetext{
${ }^{3}$ See, e.g., Williamson (2016), Biggs and Wilson (2016), Hawley (2006), Nolan (2015), and Morganti and Tahko (2017).
} 
Of the two possible responses laid out in the introduction, Dawid (2013) is perhaps the most prominent advocate of the second. In his view, given the important role that string theory plays in fundamental physics, the better option is to revise the traditional criteria of theory evaluation. After all, as historical approaches to philosophy of science have stressed, scientific methodology is not a static affair; rather, over the course of the history of science, evolutions in scientific method have been commonplace (Kuhn 1962; Laudan 1984). As Dawid argues, in addition to the more familiar methods of theory assessment that are heavily based on experiment and observation, "elements of nonempirical theory assessment are necessary" (2013: 3) in science as well, precisely in areas such as fundamental physics and cosmology, which in some contexts are closed off from experiment.

Besides defending the legitimacy of non-empirical methods, Dawid also argues that the best explanation of the deeply divergent attitudes regarding the status of string theory is that "unintentionally, string physicists have been led towards a novel conception of scientific theory appraisal" (2013: 28). This shift is referred to as "meta-paradigmatic", since it is a conflict, not between one research program and another, as in the case of Kuhnian paradigm shifts, but rather between rival conceptions of theory appraisal. Until perhaps the workshop in Munich in 2015, this meta-paradigmatic dispute between those who defend the "classical empirical paradigm" (Dawid 2013: 26), and proponents of a widened conception of scientific methodology that includes non-empirical methods of theory assessment had largely been ignored. The failure to directly address this methodological dispute, according to Dawid's analysis, is partly responsible for the heated and seemingly irresolvable nature of the dispute between proponents and critics of string theory. For convenience, let's refer to Dawid's explanation of the controversy as the "Revolution Thesis".

While Dawid has performed a commendable service by throwing light on the extraordinarily interesting philosophical issues that surround string theory — a topic that had been neglected until very recently by philosophers — and by formalizing some of the popular arguments that have been offered 
on string theory's behalf, his analysis does not, in my view, provide the best explanation of the radically conflicting attitudes toward string theory. In what follows, I will sketch and defend another explanation for the datum cited by Dawid at the outset of this section, which, as I'll argue, better accounts for the current situation in fundamental physics. As will soon become clear, the two general responses presented in the introduction are not the only ones available. Even though I'll argue against the claim that the best explanation of the conflicting assessments of string theory is one in terms of a methodological revolution, as I'll show in section 10, the three arguments for string theory that Dawid defends can be easily located in my account of the controversy.

\section{The Context of Pursuit and the Context of Justification}

Consider first what is traditionally regarded as the task of philosophy of science. It was Reichenbach (1938: 6-7) who introduced the term "context of justification" (CoJ), in contrast to what he called the "context of discovery" (CoD), with the aim of expressing the idea that philosophy of science concerns normative questions of theory-confirmation and justification and not descriptive questions of theory-construction and development. Elsewhere, Reichenbach w rites:

The act of discovery escapes logical analysis; there are no logical rules in terms of which a "discovery machine" could be constructed that would take over the creative function of the genius... with the claim that it explains these facts. In other words, logic is concerned only with the context of justification. (1958: 231)

Consider another famous expression of the $\mathrm{CoD} / \mathrm{CoJ}$ distinction, this time due to Popper:

The initial stage, the act of conceiving or inventing a theory, seems to me neither to call for logical analysis nor to be susceptible of it. The question how it happens that a new idea occurs to a man... may be of great interest to empirical psychology but it is irrelevant to the logical analysis of scientific knowledge. This latter is concerned not with questions of fact... but only with questions of justification or validity. (1959: 31-32)

Despite being one of its most ardent critics, Popper-along with several other influential figures in $20^{\text {th }}$ century philosophy of science-nevertheless endorses one of the crucial tenets of logical 
empiricism. ${ }^{4}$ According to the $\mathrm{CoD} / \mathrm{CoJ}$ distinction, the primary task of philosophical reflection on science is that of analyzing the logical and justificatory relations that hold between theory and fact. Questions about a theory's actual origin, such as the steps that led to its initial genesis and development, are thought to fall outside the CoJ and thereby outside the scope of philosophy.

Now, much more can be said about the nature and adequacy of the $\mathrm{CoD} / \mathrm{CoJ}$ distinction than space permits. What is important for our purposes is that even if there is a sharp difference between the $\mathrm{CoD}$ and $\mathrm{CoJ}$, there is at least one more stage of scientific inquiry that the Reichenbachian distinction leaves out, namely what Laudan (1977) has dubbed the "context of pursuit" (CoP). ${ }^{5}$ Whereas the CoD concerns the way that scientists ought to go about generating their hypotheses and the $\mathrm{CoJ}$ concerns the conditions under a theory is confirmed or justified given some evidence, the CoP concerns the conditions under which a theory is pursuit-worthy. Even though believing a theory seems on its surface clearly distinct from pursuing a theory, it is worth dwelling on some important differences between belief and pursuit, which will serve to motivate the distinction between beliefworthiness and pursuit-worthiness, and thereby the $\mathrm{CoJ} / \mathrm{CoP}$ distinction. ${ }^{6}$

First, although this is not entirely uncontroversial, it would seem that directly believing at will, is, if not conceptually impossible, at least not achievable as an empirical matter of fact in most cases (Williams 1970; Pojman 1999; Scott-Kakures 2000). While we have some degree of indirect control

\footnotetext{
${ }^{4}$ See, in addition, Hempel (1965), Braithwaite (1953), and Salmon (1971).

${ }^{5}$ For further critical discussion of the CoD/CoJ distinction, see the various entries in the edited volume by Schickore and Steinle (2006). For arguments that in some domains and to some extent there can be a "logic of discovery", see Schaffner (1974), Darden (1991), and Jantzen (2016).

${ }^{6}$ Throughout this paper I will employ the term "CoJ" in a way that will likely be unacceptable to anti-realists about science, such as van Fraassen (1980), who regard empirical adequacy, and not truth as the goal of science. Complicating matters considerably is the fact that according to Dawid (2013: 183-4) "the distinction between truth and empirical adequacy is out of place in string physics". Thus, even though Dawid frequently appeals to Bayesian confirmation theory, which naturally suggests a realist interpretation of his arguments, it should be stressed that Dawid is not a scientific realist with regards to string theory, at least not in the traditional sense. The issue of realism with regards to string theory is a particularly subtle one, which I won't be able to discuss in depth here. However, since much of the controversy turns on whether string theory gives us a "true picture of reality" or constitutes "scientific knowledge", presupposing here that truth is one of the goals of science is dialectically unobjectionable. As I'll further discuss below, (see fn. 34), my analysis of the string theory debate is largely unaffected by the issue of realism/anti-realism.
} 
over what we believe—by deciding to seek out a piece of evidence, for example — ordinary experience suggests that we do not have direct, voluntary control over our beliefs. When faced with powerful evidence, certain propositions almost command our assent. By contrast, whether a scientist pursues a theory looks to be a matter of direct, voluntary choice. Drafting a grant proposal, hiring a team of technicians, overseeing a series of experiments, etc. might all partly constitute pursuing a theory, and these are the sorts of behaviors that are typically within our direct, voluntary control, if anything is. Thus, one typically cannot believe a theory at will, but one can typically pursue a theory at will.

Second, while rationality demands that we do not believe theories that are inconsistent-either internally or jointly — this constraint does not apply in the case of pursuit. Clearly, while it would be irrational for some subject $\mathrm{S}$ to believe each member of a partition of hypotheses $\mathrm{H}_{1} \ldots \mathrm{H}_{10}$, it can certainly be rational for $\mathrm{S}$ to pursue $\mathrm{H}_{1} \ldots \mathrm{H}_{10}$, especially if $\mathrm{S}$ intends to employ a kind of "eliminative abduction"(Bird 2010), or "strong inference"(Platt 1964) to determine by experiment which of the ten hypotheses is true. Similarly, it can be rational for scientists to pursue two theories in different domains, even if those theories are jointly inconsistent. It would be irrational for scientists to believe both general relativity and quantum mechanics, since the two theories in their present forms are known to be inconsistent; but it is not irrational for scientists, individually, or collectively, to pursue them. Likewise, it can be rational to pursue some internally inconsistent theory, such as Bohr's atomic theory (e.g. Lakatos 1978: 55), ${ }^{7}$ for any number of reasons, even if only to solve the conceptual problems that have led to the inconsistency (Laudan 1977: 48-50). Thus, unlike in the case of belief, it can be rational to pursue a theory that one knows to be false, e.g. if the theory is inconsistent.

Third, one can typically believe a theory only if the theory is first sufficiently developed such that one can understand the propositions that are expressed by that theory and thereby assent to them.

\footnotetext{
${ }^{7}$ According to Vickers (2013: 39-75), the way in which this example is commonly invoked is somewhat misleading, since the internal inconsistency arises only in later developments of Bohr's theory.
} 
But in the case of theory-pursuit, one can pursue a theory that is not yet conceptually developed enough to be the object of a belief. If the theory is in its infancy, the central idea might be too vague, metaphorical, or suggestive to be usefully discussed in terms of the language of truth and falsity. Now, of course a scientist can judge a set of mutually exclusive, fully specified hypotheses as all being worthy of pursuit, e.g. in order to falsify alternatives. And so, it makes sense to consider fully developed theories as also being worthy of pursuit. But, unlike the CoJ, the CoP in addition covers embryonic research programs, which might, upon being further investigated, generate fully specified theories, which may then be justified by empirical methods. ${ }^{8}$ Thus, the scope of the CoP is wider than that of the CoJ, including objects of inquiry that are undeveloped.

Fourth, even though a rational agent can pursue a theory that she does not believe, pursuit still seems to involve an important kind of "cognitive attitude" toward the theory. Unlike irrelevant attitudes such as the love or hatred that a scientist might have toward a theory, cognitive attitudes, consist in "an evaluative response to some content" (Elliott and Willmes 2013: 810-11). Believing that $\mathrm{H}$ and having a degree of belief in $\mathrm{H}$ greater than .5 are paradigmatic instances of cognitive attitudes, but doxastic attitudes such as these are inappropriate in giving an account of the CoP. Instead, the cognitive attitude that ought to be associated with the CoP is what usually is called "acceptance." In ordinary English "to accept" is often used interchangeably with "to believe". For example, "I accept that God exists" and "I believe that God exists" seem synonymous in ordinary English. ${ }^{9}$ Nevertheless, it is common among philosophers to make a distinction between acceptance and belief (e.g. Cohen 1992; Audi 2008; Bratman 1999; van Fraassen 1980). One useful, general account of acceptance is the one provided by Elliott and Willmes, who define "acceptance" as follows:

\footnotetext{
8 Thanks to an anonymous reviewer for suggesting that I note this key difference between the CoP and the CoJ. 9 Indeed, Laudan contrasts the "context of pursuit" with the "context of acceptance", where by "acceptability", he means, as in ordinary English, "worthy of belief" (1977: 110). As a result, this increasingly popular terminological choice of using "acceptance" in a way that is severed from belief, which I admittedly perpetuate, is in some ways unfortunate.
} 
A subject $\mathrm{S}$ accepts a hypothesis (or model, theory, etc.) $\mathrm{H}$ if and only if $\mathrm{S}$ presupposes $\mathrm{H}$ for specific reasons in her deliberation. (2013: 811)

On this account, acceptance is left deliberately vague so that there will be different, particularized notions of acceptance, such as acceptance for reasons of simplifying a task, for reasons of drafting regulatory policy, or for reasons of furthering future investigation. The latter notion of acceptance is most relevant for our purposes, and involves, as van Fraassen (1980: 12) puts it "a commitment to confront any future phenomena by means of the conceptual resources of this theory."

Despite these differences between belief and acceptance, one commonality they share is that both come in degrees. Typically, degrees of belief, or credences, are tracked by and for some, conceptually identified with betting behavior (De Finetti 1974). If the agent believes with certainty, i.e. with a credence of 1 , that some proposition $p$ is true, then she would be willing to purchase a bet that pays $\$ 1$ if $p$ is true at a price $\leq \$ 1$, if she has a credence of $1 / 2$ that $p$ is true, then she would be willing to purchase a bet that pays $\$ 1$ if $p$ is true at a price $\leq \$ .5$, etc. Analogously, if we think of acceptance as consisting in a commitment to pursue a theory $\mathrm{T}$, then the degree to which $\mathrm{T}$ is worthy of pursuit will correspond to the strength of commitment in T that is warranted. Likewise, one's actual degree of acceptance of T will corresponds to one's actual strength of commitment to T.

Although I have urged that there is a distinction between belief and pursuit, and more broadly between the $\mathrm{CoJ}$ and the $\mathrm{CoP}$, it is important to stress that the CoP, like the $\mathrm{CoJ}$, raises genuinely normative and evaluative questions. For instance, it is natural to ask questions regarding some theory T, "Is T worthy of pursuit?", "Ought scientists pursue T?", "Is it rational for scientists to continue to pursue T?”, etc. Thus, the CoP concerns questions that are similar in form to the kinds of questions that are asked in the CoJ: "Is T worthy of belief?", "Ought scientists believe T?", "Is it rational for scientists to believe T?", etc. Since the sorts of questions that can be raised in the CoP are normative, they are appropriate candidates for philosophical reflection. A philosophy of science without some account of the ways in which judgements of pursuit-worthiness are made would be badly incomplete. 


\section{The Conflation Thesis as the Explanation of the Controversy}

With this distinction between the CoP and the CoJ in hand, we are now in a position to offer a better explanation for the radical disagreement over the current status of string theory. Rather than characterizing the present situation in fundamental physics as a failure to abide by the traditional canons of scientific method, as many critics of string theory have averred, or as an incipient and hitherto unnoticed methodological revolution, as Dawid has argued, instead I propose that the better explanation is that parties on both sides of the debate have failed to properly respect the distinction between the CoP and the CoJ. In both critiques and defenses of string theory, the concepts of beliefworthiness and pursuit-worthiness are regularly conflated; and moreover, the sorts of distinctions that I have pointed out between pursuit—along with its concomitant cognitive attitude acceptance_and belief are frequently ignored. For convenience, let's refer to the claim that both proponents and opponents of string theory regularly conflate considerations that belong to $\mathrm{CoP}$ with considerations that belong to the CoJ in the foregoing ways as the "Conflation Thesis". If the Conflation Thesis is true, as I'll attempt to argue, then this will elegantly explain the heated and seemingly intractable debates that have raged over the legitimacy of string theory.

A crucial source of initial motivation for the Conflation Thesis is that the question of what makes a hypothesis, theory, model, research program, etc. worthy of pursuit has been largely ignored by philosophers of science. As one proponent of pursuit remarks upon the neglect of the CoP, "Do not philosophers of science have a responsibility to investigate this sort of evaluation and justification also?" (Nickles 2006: 159). ${ }^{10}$ It might seem incredible that philosophers of science have largely neglected to address this question. However, consider the most discussed methodological frameworks throughout the history of philosophy of science, including hypothetico-deductivism (Whewell 1840),

\footnotetext{
${ }^{10}$ Instead of introducing a new context, Nickles (2006: 159) separates the CoJ into two components "epistemic appraisal" (EA) and "heuristic appraisal" (HA). My use of "CoJ" corresponds to his "EA" and my "CoP" to his "HA".
} 
inductivism (Mill 1843), the logical probability program (Carnap 1950), falsificationism (Popper 1959), likelihoodism (Sober 1990), IBE (Lipton 2004), and subjective Bayesianism (Howson and Urbach 2006). All belong to the CoJ, either directly or indirectly, being primarily concerned with question s of scientific knowledge, epistemic justification, evidential support, corroboration, or confirmation. For example, neither subjective Bayesianism nor IBE—currently the two most prominent approaches for understanding scientific inference (Henderson 2014) — says anything about when a theory is worthy of pursuit, at least not in their canonical formulations. The normative constraints of Bayesianism determine what counts as a rationally permissible credence function at a given moment and over time. IBE claims that the hypothesis that explains the evidence better than its rivals is that which we ought to infer to be true. Clearly then, both frameworks are concerned with what an agent ought to believe. ${ }^{11}$

To be sure, there have been at times investigations into theory-pursuit, but it is undoubtedly true that questions concerning the $\mathrm{CoP}$ have always taken a backseat to questions concerning the CoJ. ${ }^{12}$ One consequence of the fact that inquiry into the CoJ has by far predominated inquiry into the $\mathrm{CoP}$ is that we do not have any sophisticated, well-researched, general philosophical models of theorypursuit. Since the distinction between the CoJ and the CoP is infrequently acknowledged in philosophy of science, and since we do not have anything close to a fully fleshed-out account of theory-pursuit to which we might appeal in order to resolve the question of string theory's pursuit-worthiness, it will come as no surprise on my account that philosophical reflection on the status of the theory sometimes manifests itself as a seemingly intractable deadlock.

\footnotetext{
${ }^{11}$ Questions about evidence, support, favoring, or confirmation are not directly normative, and yet still belong to the CoJ. This is explained by the fact that such questions are normative in an indirect sense. For instance, the connection between justification and evidence may be mediated by some evidentialist thesis (e.g. Conee and Feldman 2004; McCain 2014), according to which one is justified in believing $\mathrm{H}$ if and only if one has sufficient evidence for $\mathrm{H}$.

12 See, for instance, (Whitt 1990, 1992), Achinstein (1993), French (1995), Nickles (2006), Šešelja \& Straßer (2014), and Franklin and Fischbach (2016).
} 


\section{The Conflation of the Two Contexts in Dawid's Account}

Having offered some initial motivation for the Conflation Thesis, it is now time to take a closer look at some of the existing commentary to show that the conflation of the CoP and CoJ is not uncommon. ${ }^{13}$ In fact, a failure to distinguish between the CoP and the CoJ occurs on both sides of the debate, including in Dawid's account of the controversy and in subsequent reactions to his book. ${ }^{14}$

Recall that Dawid argues that the best explanation of the radically divergent views on the status of string theory is that a methodological revolution of sorts is underway that has not been openly acknowledged by opponents of the theory. According to Dawid (2013: 30-8), these non-empirical methods include three patterns of argument: 1) the no alternatives argument (NAA), according to which string theory gains support from its being the only live option for unifying the fundamental forces of nature; 2) the argument of unexpected explanatory coherence (UEA), according to which string theory gains support from the explanatory interconnections that it entails between seemingly unrelated phenomena; and 3) the meta-inductive argument (MIA), according to which string theory gains support from the success of other, similar theories in high energy physics. Given the technological impossibility of directly testing the core postulates of string theory, those working on the theory have tacitly committed themselves to the legitimacy of these non-empirical methods of theory assessment. ${ }^{15}$

However, the datum cited in section 4 that Dawid hopes to explain by means of introducing and defending the idea of non-empirical theory assessment is crucially ambiguous. He notes that string

\footnotetext{
${ }^{13}$ Primarily, I will attempt to show that the Conflation Thesis is a better explanation than the one offered by Dawid. I will not compare the Conflation Thesis with the Sociological Thesis. Perhaps some of the explanation of the controversies over string theory are due to the phenomena pointed out by Smolin and Woit, but as I hope to show, the persistent failure to distinguish the $\mathrm{CoP}$ from the $\mathrm{CoJ}$ is at least partly responsible for the current controversy.

${ }^{14}$ It should be noted that Rovelli also accuses Dawid of a similar conflation, writing that Dawid has "obfuscated the crucial distinction between ["preliminary appraisal"] and validation" (2016: 2). In light of this, one may consider my analysis of the string theory debate as an extended defense of Rovelli's position.

15 The term "non-empirical theory assessment" is slightly misleading in that these arguments clearly rely on some empirical data - observations about the history of research in physics, for instance. But the sense in which the arguments are non-empirical is that the observations used to support string theory are not ones that are directly predicted by the theory itself (Dawid 2013: 38).
} 
theorists "express a remarkably strong trust in their theory's viability" and that the theory is "wellestablished and authoritative” (2013: 19). In framing the controversy, Dawid frequently employs similar terms, considering whether we ought to have "a high degree of trust" (2013: 7) in string theory, or whether string theory has "scientific viability" (2013: 42), or whether the theory is "well-established" (2013: 47). But these terms are all ambiguous between the CoP and the CoJ.

By claiming that string theorists have "a high degree of trust" in string theory, this claim can mean either i) that string theorists have a high degree of belief in string theory, or ii) that string theorists judge that string theory is, to a high degree, worthy of pursuit, and therefore ought to be accepted in the relevant sense. In fact, in a lucid analysis of rational trust, Frost-Arnold (2014: 1958) argues at length that "sometimes [trust] involves the cognitive attitude of belief, while other times it involves the attitude of acceptance."16 Likewise, terms such as "well-established" and "viable" can be given a CoJ reading, whereby we ought to have a high degree of belief in theories that are well-established or viable, or a CoP reading, whereby such theories are highly worthy of pursuit.

In addition, notice that the terms "theory assessment", and its synonym, "theory evaluation" (2013: 29) are also ambiguous between the CoP and the CoJ. We can assess or evaluate a theory $\mathrm{T}$ from the CoJ, asking if $\mathrm{T}$ is supported by the evidence, is rational to believe, constitutes scientific knowledge, etc. But we can also assess or evaluate $\mathrm{T}$ from the CoP, asking if $\mathrm{T}$ is promising, worthy of pursuit, ought to be further investigated, etc. Of course, the reading that we ought to charitably adopt in this case is a CoP reading. Importantly, however, Dawid at times makes claims that suggest the intended reading of "theory assessment" in his analysis is that of the CoJ.

For instance, in a discussion contrasting his non-empirical theory assessment with what he calls "the classical paradigm", Dawid (2013: 39-42) remarks upon how it is that scientists become

\footnotetext{
${ }^{16}$ It should be noted that Frost-Arnold's disjunctive account of trust is concerned with "interpersonal trust" and is thus supposed to determine the conditions under which statements of the form "A trusts B to $\varphi$ " are true. However, this account of trust in terms of belief or acceptance can be usefully invoked here in the case of trusting a theory.
} 
"entitled to believe in their theory" and when it is that a "scientific theory can constitute knowledge about the world"- transitioning immediately into a discussion of popular models of theory assessment, including hypothetico-deductivism and subjective Bayesianism. But, as I pointed out in section 6, both hypothetico-deductivism and subjective Bayesianism belong to the CoJ, and not the CoP. Both models of scientific inference tell us under what conditions we ought to think that a hypothesis is confirmed by a body of evidence, where presumably some high degree of theory confirmation will suffice for scientific knowledge. The hypothetico-deductive model states that a hypothesis $\mathrm{H}$ is confirmed by the evidence $\mathrm{E}$ just in case $\mathrm{H}$ deductively entails $\mathrm{E}$ at $\mathrm{t}_{1}$ and at $\mathrm{t}_{2} \mathrm{E}$ is true; whereas the standard qualitative account of Bayesian confirmation states that $\mathrm{H}$ is confirmed by E just in case $\operatorname{Pr}(\mathrm{H} \mid \mathrm{E})>\operatorname{Pr}(\mathrm{H})$ at $\mathrm{t}_{1}$ and at $\mathrm{t}_{2} \mathrm{E}$ is true. But as N.R. Hanson aptly observed 60 years ago, "[the] H-D account is helpful only when discussing the argument of a finished research report" (1958: 2). Clearly, the same holds true of Bayesianism, and as a result, neither model of scientific inference says anything directly about when a theory is worthy of pursuit.

Notably, some of Dawid's staunchest critics, such as the physicists George Ellis and Joe Silk have interpreted Dawid's claims about theory assessment precisely as belonging to the CoJ, and not the CoP. In a passionate editorial published in Nature titled, "Scientific method: Defend the integrity of physics" (2014), Ellis and Silk, react negatively to the proposal of Dawid to widen the canons of theory assessment, characterizing this idea as "breaking with centuries of philosophical tradition of defining scientific knowledge as empirical" (2014: 321), and at the end of their piece call for a conference to be organized to debate what counts as acceptable scientific method.

This ambiguity between the CoJ and the CoP leads to a crucial dilemma for Dawid's explanation of the controversy — what I called the Revolution Thesis. On the one hand, if we interpret Dawid's thesis as a claim about the CoJ, then it would indeed be accurate to describe what is happening 
in fundamental physics as a kind of Kuhnian meta-paradigm shift. ${ }^{17}$ In this case, the urgent reactions of Ellis and Silk (2014) would be understandable. However, in giving Dawid's Revolution Thesis a $\mathrm{CoJ}$ reading, we would be required to attribute to string theorists unjustified doxastic attitudes that most upon reflection would reject. Given the widely acknowledged point on both sides of the debate that string theory is incomplete, it would be uncharitable to interpret proponents of string theory as claiming that the theory ought to be highly positively appraised from the point of view of the CoJ. As Camilleri and Ritson (2015: 46) note "few string theorists would claim that string theory, as it currently stands, gives "a true picture of the world." ${ }^{18}$ For this reason, the debate over string theory should be clearly framed in terms of whether the scientific community ought to continue to pursue string theory, not in terms of whether string theory already constitutes scientific knowledge. ${ }^{19}$

\footnotetext{
17 Thanks to an anonymous reviewer for pointing out that at the Munich conference, Dawid explicitly endorsed the claim that the non-empirical arguments for string theory are "reasons to believe", and not simply "reasons to pursue" the theory. As I'll discuss in section 10, these arguments are better off if interpreted as reasons to pursue string theory. 18 Although Camilleri and Ritson (2015) cite many examples of prominent physicists who are extremely tentative about their views on string theory, including Greene (1999, p. 18) who calls it a "work in progress", Johnson (2006), who calls it merely "promising", Witten (2005, p. 1085) and Duff (2013, p. 184), who say it is "on the right track", etc., an anonymous reviewer objects to this characterization, writing that string theory is very frequently presented "as an incomplete, but already confirmed theory" and that "a generation of young physicists have been educated into believing that String theory describes the world." Instead, according to the anonymous reviewer, the claim made by Polchinski (2016) that the Bayesian probability of string theory is $98.5 \%$, is more characteristic of the one side of the debate. First, it is worth mentioning that this calculation, which is cited also by Rovelli (2016), is not, it would seem, intended to be taken too seriously. As Polchinski writes, "Bayesian analysis is not the point. It is not even one percent of the point. Every word spent on this subject is a wasted word" (2016: 2). Furthermore, Polchinski concludes, "these statistical games are fun, but they are not the real point"; rather, the point is that "[ $t$ ] here is some fascinating physics to explore right now" (2016: 10). Here, Polchinski seems most concerned about the claim that string theory is worthy of pursuit, despite his admittedly odd choice to engage in "statistical games". Second, I do not doubt that some proponents of string theory discuss the theory in the language of "belief", when instead they should discuss the theory in the language of "pursuit". This is precisely to be expected on my analysis of the controversy. However, as I discuss below, critics of string theory are also less clear about the distinction than is desirable.

${ }^{19}$ As Camilleri and Ritson (2015: 46) and Rickles (2013: 78) have argued, Cartwright and Frigg (2007: 15) miss this point when they write that there is at present insufficient reason to think that string theory "gives us a true picture of the world", and that therefore the theory is not "progressive" (Cartwright and Frigg 2007: 15). To be sure, both Camilleri and Ritson (2015: 46) and Rickles (2013: 77-8) show a clear appreciation for the point that the crux of the debate is whether it is rational to continue to pursue string theory, not whether it is rational to believe string theory. However, my account is novel in that unlike Camilleri and Ritson and Rickles, I provide an extended analysis of the distinction between the $\mathrm{CoJ}$ and the CoP, and, moreover, I posit the conflation of the two contexts as a possible explanation for the intractable character of the string theory debates.
} 
But if, on the other hand, we give the Revolution Thesis a CoP reading, rather than a CoJ reading, then this undermines Dawid's central claim that "the criteria of theory assessment have been significantly transformed in fundamental physics in recent decades" (2013: 2), which in turn undermines the corresponding explanation of the current situation in fund amental physics. The reason that a CoP reading undercuts the explanatory power of the Revolution Thesis is that, while it is plausible to claim that there is a "classical scientific paradigm" (2013: 42) governing when some theory is sufficiently confirmed, or constitutes scientific knowledge, it is implausible to claim that there is classical scientific paradigm governing when some theory is worthy of pursuit.

As I pointed out when articulating the Conflation Thesis in section 6, the formal frameworks that loom large in the history of reflection on scientific inquiry by scientists and philosophers all belong to the CoJ. For a variety of reasons explored by Nickles (2006: 170-5), including the influence of the $\mathrm{CoD} / \mathrm{CoJ}$ distinction and the seeming resistance of the CoP to precise formalization, little philosophical research has been conducted on questions of fertility, theory promise, and pursuitworthiness. But if there is no widely accepted paradigm governing the $\mathrm{CoP}$, then it follows that there cannot be the kind of revolution in the criteria of theory assessment posited by Dawid. And without a widely accepted account of theory-pursuit to act as a foil, the Revolution Thesis, given a CoP reading, is insufficient to explain the controversies surrounding the scientific legitimacy of string theory. For this reason, Dawid's analysis of the drastically divergent views on the status of string theory and other speculative theories in fundamental physics is explanatorily deficient.

Indeed, my explanation of the current situation in fundamental physics in terms of the Conflation Thesis is strengthened by the fact that there is little recognition of and research examining the CoP, and as a result, nothing close to a widely agreed-upon account of theory-pursuit. In the absence of an account of theory-pursuit, we should expect to see trenchant disagreement about whether string theory is worthy of pursuit. Moreover, for want of a philosophical model to guide us 
in the CoP, the natural move to make is to appeal to traditional accounts of scientific inference and theory confirmation to help adjudicate the dispute. As tempting as it is to defer to traditional accounts of scientific inference here, this move should be resisted. As I have argued, there is a distinction between pursuing a theory and believing it. Given this distinction, there is little reason to think that being highly positively appraised from the point of view of the CoJ is necessary or sufficient for being highly positively appraised from the point of view of the CoP.

While my defense of the Conflation Thesis has largely consisted in attempting to show that the CoJ and the CoP are not properly distinguished in Dawid's treatment of the controversy, this failure to respect the distinction between the two contexts occurs in popular writings on string theory with considerable frequency. ${ }^{20}$ In addition to Cartwright and Frigg (2007: 15), consider the following statement by Woit (2006: 248), an ardent critic of string theory, which blatantly runs together both the $\mathrm{CoP}$ and the CoJ: "The surprising thing is that [Susskind] and other prominent theorists don't see [the lack of predictions] as a reason to give up on the theory, but instead choose to believe that the theory must be true, even though it can't predict anything." Whether Susskind believes that the theory is true is doubtful, ${ }^{21}$ but what is important here is that this statement objectionably conflates issues pertaining to the $\mathrm{CoJ}$ and issues pertaining to the CoP. Even if string theory does not predict any novel facts, it does not yet follow that we ought to give up on the theory, as Woit suggests here.

I do not mean to suggest, however, that critics of string theory categorically think that the theory is unworthy of pursuit. For instance, the physicist Carlo Rovelli, commenting on current attempts to formulate a theory of quantum gravity, writes: "The tentative theories we have, such as loop gravity, strings or noncommutative geometry, are courageous attempts that are worth pursuing but badly incomplete" (2005: 259, emphasis mine). Similarly, after provocatively asking the question: "So,

\footnotetext{
${ }^{20}$ For some additional evidence that conflating the CoJ and the CoP is common, see Franklin and Fischbach (2016: $97-$

8) who argue that social constructivists about science such as Pickering (1984) regularly conflate the two contexts.

${ }^{21}$ See the tentative attitude that Susskind (2013) takes to string theory.
} 
is string theory still worth studying, or should it be declared a failure, as some suggest?" (2006: 198, emphasis mine), Smolin goes on to admit that string theory is indeed worthy of pursuit. His main quarrel seems to be that string theory deserves less attention than it currently receives and that we ought to develop other approaches to unifying the various forces of fundamental physics (Smolin 2006: 198-9).

However, while Smolin sometimes appreciates the distinction between the question of whether string theory ought to be pursued and the question of whether it ought to be believed frequently he speaks of those who "believe in" string theory, when for example, he writes about proposals to revise the canons of scientific method (2006: 169). But like the term "trust", the locution "believe in", is ambiguous between believing that the theory is true and judging that it is worth pursuing. So, while it might be the position of Smolin and other critics of string theory that the theory is worth pursuing, but just not empirically confirmed, ultimately, this failure to clearly distinguish between the CoP and the CoJ has obscured what is really at stake. To avoid needless controversy, it would be wise to be clear about the distinction between the CoP and the CoJ.

\section{Objection: The CoP Reduces to the CoJ}

While I have urged a distinction between the CoJ and CoP, one might object that the distinction on which the Conflation Thesis depends is not so sharp. Instead, one might argue that the norms that govern theory-pursuit are parasitic on the norms that govern epistemic justification. After all, why else would we pursue a theory unless we have good reason to believe that the theory at least has some good chance of being true? On this view, the same sorts of considerations that lead us ultimately to believe that some theory is true are also those that lead us to pursue that theory in the first place. For convenience, let's refer to this sort of view about the relationship between the CoP and the CoJ simply as "reductionism". If reductionism is true and consequently there is no sharp distinction between the CoP and the CoJ, then-the objection goes-it is not a problem that both proponents and opponents of string theory do not clearly distinguish between pursuit-worthiness and 
belief-worthiness. The critic of string theory might be simply interpreted as claiming that the track record of string theory from the perspective of the $\mathrm{CoJ}$ is so dismal, and since the CoP depends on the CoJ, it is likewise dismal from the perspective of the CoP. If the CoP reduces to the CoJ, then this reduction undermines the explanatory power of the Conflation Thesis.

Indeed, this idea that the $\mathrm{CoP}$ is in some sense dependent on the $\mathrm{CoJ}$ forms the basis of one of the few general accounts of theory-pursuit. According to the account sketched by Šešelja and Straßer, "a theory is epistemically worthy of further pursuit to the extent it is potentially epistemically justified" (2014: 3113). In their account of theory-pursuit, Šešelja and Straßer lean on Bonjour's (1985) coherentist theory of justification and argue that a theory is worth pursuing to the extent that it is “potentially coherent"-where this consists in potential explanatory power, potential inferential density, potential consistency, and having a programmatic character (2014: 3123). Here, the guiding principle is that, "standards of epistemic justification suitable for the context of acceptance [i.e. justification] can be modified and adapted for the context of pursuit” (Šešelja and Straßer 2014: 3138).

With this idea in mind, one might object that the classical paradigm of theory assessment against which Dawid argues can be marshalled to give an account of the CoP. For example, one might argue that a theory needs to make a certain number of novel predictions $n$ in order to constitute scientific knowledge, and likewise a theory needs to make a certain number of novel predictions $m$ after a certain period of time $t$, where of course $m<n$, in order to constitute a theory that is worthy of continued pursuit. For convenience, let's call this account of pursuit the "predictivist account". If novel predictions are the means by which we gain scientific knowledge, and the means by which a theory is judged worthy of pursuit, as the predictivist account claims, then the CoP is clearly reducible to the CoJ. Indeed, this picture more or less corresponds to the well-known view of theory assessment put forward by Lakatos (1978), which gives pride of place to novel predictions. According to Lakatos, "predictions of novel facts...constitute serious evidence for a research program" (1978: 114), and so 
too, "a research programme is said to be progressing as long as...it keeps predicting novel facts with some success" (1978: 112). Thus, novel prediction is crucial in the CoJ and the CoP for Lakatos. If this perspective is right, then there would be little reason to distinguish the two contexts.

\section{A Response to the Reductionist Objection}

A full defense of the assumption that the CoP cannot be reduced to the CoJ would, of course, amount to fully articulating and defending an account of theory-pursuit - a task which is beyond the scope of the present inquiry. Even so, there is good reason to think that neither the proposed reduction above, nor any reduction in general, will succeed.

First, it is important to recognize that the Lakatosian-inspired predictivist account needs to be given a deeper justification. Why think that novel predictions are of fundamental importance for generating either scientific knowledge or theories that are worthy of pursuit? Here, it is natural to appeal to the Bayesian framework. There is some dispute about how precisely to characterize what makes a prediction "novel", 22 but one plausible Bayesian explication is in terms of the prior probability of the evidence before learning that the evidence is true. So, the Bayesian might say that some observation or piece of evidence $\mathrm{E}$ is novel if and only if E's being the case would be surprising. Moreover, the best way to cash out E's being surprising is simply in terms of the prior probability of E, i.e. $\operatorname{Pr}(\mathrm{E})$. If we look at one mathematical form of Bayes' Theorem, it's easy to see that the successful prediction of a novel fact is highly epistemically desirable:

$$
\operatorname{Pr}(\mathrm{H} \mid \mathrm{E})=\frac{\operatorname{Pr}(\mathrm{H}) \operatorname{Pr}(\mathrm{E} \mid \mathrm{H})}{\operatorname{Pr}(\mathrm{E})}
$$

\footnotetext{
22 See, for instance, Musgrave (1974) who distinguishes between temporal novelty, i.e. a theory predicts an observation that was unknown at the time that the theory was articulated; heuristic novelty, i.e. a theory was not constructed solely for the purpose of explaining an observation, and theoretical novelty, i.e. a theory predicts an observation that is not predicted by some prominent rival theory.
} 
Since $\operatorname{Pr}(\mathrm{E})$ is in the denominator, as the value of $\operatorname{Pr}(\mathrm{E})$ gets smaller, the value of $\operatorname{Pr}(\mathrm{H} \mid \mathrm{E})$ - the posterior probability - gets larger, provided of course that the product of the two terms in the numerator does not equal zero or one. If $\mathrm{H}$ predicts $\mathrm{E}$, in the sense of entailing $\mathrm{E}$, or rendering $\mathrm{E}$ highly probable, and if $\mathrm{E}$ is, with respect to $\mathrm{H}$, a "novel prediction", e.g. $\operatorname{Pr}(\mathrm{E})=.0001$, then the observation that $\mathrm{E}$ is the case might dramatically increase the posterior probability of $\mathrm{H}$.

This elegant explication of the epistemic value of novel predictions suggests that the reductionist's account of theory-pursuit ought to be formulated in Bayesian terms. To see how this might work, it is instructive to reflect on how a Bayesian might connect credences (i.e. degrees of belief), its primary object of appraisal, with the more coarse-grained attitude of full belief, the object of appraisal of traditional epistemology. One intuitively plausible bridge principle is called the "Lockean thesis", according to which, "it is epistemically rational for us to believe a proposition just in case it is epistemically rational for us to have a sufficiently high degree of confidence in it" (Foley 1992: 111). Now, while the Lockean thesis is rendered problematic by the so-called "lottery paradox"(Kyburg 1961), plausibly, there remains a close conceptual connection between rational credences and rational full-belief. ${ }^{23}$ At the very least, the following sufficient condition obtains: if it is rational to believe that $p$, then one ought to have a credence in $p>.5$; otherwise, it would be permissible to believe that $p$, even though one has greater, or equal, confidence in $\sim p$, which seems absurd.

\footnotetext{
23 The lottery paradox shows that the Lockean Thesis, assuming some plausible rational constraints on full beliefs, leads to objectionable results. Suppose that a sufficiently high credence is .99 , and so it is rational to believe that $p$ if and only if it is rational to have a .99 degree of belief in $p$. Now, suppose there is a fair lottery in which there are 100 tickets $T_{1}$, $\mathrm{T}_{2}, \ldots \mathrm{T}_{100}$. Then, according to the Lockean Thesis it is rational to believe that $\mathrm{T}_{1}$ loses, it is rational to believe that $\mathrm{T}_{2}$ loses, and so on, up to and including $\mathrm{T}_{100}$, since the probability that each ticket will lose is .99. But it is also plausible that the relation "is rational to believe" is closed under conjunction. Given this closure principle, it is rational to believe "T 1 loses \& $\mathrm{T}_{2}$ loses \&...\& $\mathrm{T}_{100}$ loses". But then, the Lockean Thesis says it is rational to believe that no ticket will win, which violates the assumption that the lottery is fair. The result generalizes such that any view which links rational belief by way of a biconditional with some credence threshold less than 1 will be subject to a similar argument. If one increases the threshold to $>.99$, then one will only have to increase the number of tickets in the lottery.
} 
Similarly, a Bayesian account of theory-pursuit might adopt a threshold view connecting credences with pursuit-worthiness. According to this view, if it is rational to pursue some theory T, then one has a rational credence in $\mathrm{T}$ greater than some determinate threshold $r$. Clearly, in the case of pursuit, $r$ should be less than .5-perhaps .1 or .2- to account for the fact that when we are wondering whether we ought to pursue $\mathrm{T}$, this is often, though not always, in a context in which $\mathrm{T}$ is a new theory. If T is a new theory, then typically T won't yet have been subjected to empirical testing, and so won't yet have had the chance to prove itself probable. If on a Bayesian view of pursuit we adopted a high value for $r$, then it would objectionably follow that very few theories would be worthy of pursuit. A Bayesian account of theory-pursuit, such as this one, formalizes the natural thought that, unless a theory has a reasonable chance of being true, that theory ought not to be taken seriously.

Crucially, however, this Bayesian view of theory-pursuit suffers from a problem that has already been hinted at upon introducing the distinction between pursuit and belief in section 5; namely, it can be rational to pursue a theory, or a conjunction of theories, that one knows to be false. If a theory $\mathrm{T}$ is known to be false, then presumably one ought to have either a credence of zero in $\mathrm{T}$, or a credence that is extraordinarily low, e.g. $\operatorname{Pr}(\mathrm{T})=.000001$. The kind of example that I considered earlier was a theory that is internally inconsistent, e.g. Bohr's atomic theory, or two theories that are jointly inconsistent, e.g. the general theory of relativity and quantum field theory. According to the axioms of the probability calculus, an internally inconsistent theory — or the conjunction of jointly inconsistent theories - ought to be assigned a probability of 0 . But then, of course, such theories would not ever be rational to pursue according to this Bayesian account, which is clearly objectionable.

What's more, these cases are not atypical. It is a commonly repeated aphorism in statistics that "all models are false". ${ }^{24}$ This saying is doubtless an exaggeration, but it highlights a fact that is

\footnotetext{
${ }^{24}$ The quotation is often attributed to the $20^{\text {th }}$ century statistician George Box, where the full quotation is alleged to be "all models are false, but some are useful" (Briggs 2016: 126).
} 
becoming increasingly appreciated by philosophers of science, namely that many scientific models contain ineliminable, false idealizations (Elgin 2007; Batterman 2009; Bokulich 2011; Potochnik 2017). For example, a model of oceanic heat uptake which assumes that the ocean is infinitely deep cannot plausibly be true (Maddy 1992). Nonetheless, often these models have explanatory power and provide understanding, or have some other scientific virtue. Presumably then, these models are worthy of pursuit, despite being false, strictly-speaking. Any view according to which a theory needs to be appreciably positively appraised from the $\mathrm{CoJ}$ in order to be positively appraised from the CoP would make it irrational to continue to pursue much model-based scientific research.

But the strongest reason to think that the CoP cannot be reduced to the $\mathrm{CoJ}$ is that pursuitworthiness additionally involves considerations other than those that are epistemic. ${ }^{25}$ While by definition, only epistemic values, i.e. those that are indicative of truth or falsity, are relevant in the CoJ, it is plausibly the case that CoP covers not only values that are epistemic, but also ones that are nonepistemic, including those of a prudential and or ethical sort. ${ }^{26}$ In some contexts, depending on the goals of inquiry, epistemic considerations can be relevant in the CoP. However, one aspect of pursuitworthiness that seems necessary for any viable account is the recognition of its undeniable practical dimension. For example, it cannot be said that we ought to pursue a theory that contains, say, equations that take 10 million years to write down. Since "ought" implies "can", practical feasibility must act as a constraint on what theories are rational to pursue. Considerations such as cost of research, whether the research will lead to "significant truth" (Kitcher 1993: 94), the moral permissibility of some necessary experimental test, or whether research on some theory will lead to the discovery of mathematical or computational techniques that are useful in other domains, may all

\footnotetext{
25 See Nickles (2006: 164-9) for a list of reasons to distinguish the CoP from the CoJ. See also Whitt (1990: 470-2). 26 Šešelja and Straßer (2014) attempt to distinguish between "epistemic pursuit-worthiness" and "practical pursuitworthiness", but I am skeptical that the interweaving epistemic and pragmatic considerations that appear to characterize the CoP can be neatly separated in this way.
} 
play a role in the CoP. Because it is plausibly the case that such non-epistemic factors are also relevant to the $\mathrm{CoP}$ and because such factors, are by definition, out of place in the CoJ, reductionism fails in principle. In this way, we can neutralize a strong objection to the Conflation Thesis.

\section{Recasting Dawid's Non-Empirical Theory Assessment in the CoP}

As I've argued, the Revolution Thesis, as articulated by Dawid to account for the current controversies in fundamental physics, suffers from serious difficulties. In its place, I have proposed the Conflation Thesis as the better explanation. As I have attempted to show, there is a genuine distinction between the $\mathrm{CoJ}$ and the $\mathrm{CoP}$, this distinction is regularly conflated or not clearly respected in discussions of string theory, and moreover, we do not have anything close to a widely accepted account of theory-pursuit. As a result, it is no surprise to see radically conflicting views regularly espoused on the scientific legitimacy of speculative theories in fundamental physics.

Now, one of the concerns that has exercised Dawid is to find a principled way to reject the "strict dichotomy between scientific knowledge established by empirical confirmation on the one hand and mere speculation on the other" (2013: 126). But the better way to do this, on my view, is to acknowledge that, in addition to scientific knowledge, or rational belief, there exists the cognitive attitude of acceptance, where acceptance consists in commitment to a theory or research program as worthy of pursuit. While I have not defended an account of theory-pursuit and have only hinted at some of the general features of pursuit-worthiness, if we look closely at the arguments constituting non-empirical theory assessment, we will see that they are in fact better located in the CoP.

First, let's grant that the lack of any viable alternatives to a theory, given some defensible, but not entirely uncontroversial assumptions about the character of the research process, can confirm the theory according to the Bayesian account of confirmation, as Dawid et al. (2015) rigorously prove. ${ }^{27}$

${ }^{27}$ See Herzberg (2014) for a critical discussion of the assumptions required by the proof of Dawid et al. (2015). 
Even so, it is doubtful that the NAA will be sufficient to afford us scientific knowledge of some theory in the majority of cases. Although Dawid et al. (2015) have admirably demonstrated that there are conditions under which the NAA is probabilistically valid—a significant result no doubt—marshaling the NAA in the CoJ will surely prove controversial in any given case, especially as an argument for believing that the theory that is the only game in town is thereby also true. ${ }^{28}$

Instead, the NAA makes more sense if employed as an argument for continuing to pursue some theory or research program. ${ }^{29}$ Indeed, this seems to be how the argument is understood by disputants in the string theory debate. For example, Woit writes: "[v]arious non-scientific arguments are frequently made for continuing to pursue research in superstring theory. The most common is that 'it's the only game in town"' (2006: 224, emphasis mine).${ }^{30}$ Moreover, the deployment of the NAA in the CoP is much more convincing in its application. If it is true that some theory $\mathrm{T}$ is the only live option for explaining some phenomena $\mathrm{P}$, and if we do not have compelling reason to think that $\mathrm{P}$ cannot be given some underlying explanation, then T seems worthy of pursuit. Even if T suffers from empirical and conceptual problems, continuing to pursue $\mathrm{T}$ if it is our only available option at the

\footnotetext{
28 As Dawid (2016: 204) admits: "It has to be emphasised that a general argument for the legitimacy of non-empirical confirmation by no means implies that each individual deployment of non-empirical confirmation is convincing."

${ }^{29}$ One might think that the NAA as an argument to pursue string theory is undermined by the existence of alternatives to reconciling quantum mechanics and general relativity, such as the approach known as "loop quantum gravity". In response to this worry, first it should be noted that as an argument for theory-pursuit, it seems that the NAA could be weakened without much consequence. If a theory $\mathrm{T}$ has only one alternative $\mathrm{T}^{*}$, and both are similar in their epistemic status, as plausibly, both string theory and loop quantum gravity are, then there seems to be no problem with accepting that both are worthy of pursuit. If there are very few alternatives to $\mathrm{T}$, and there is little advantage in these alternatives over $\mathrm{T}$, then it seems rational to pursue $\mathrm{T}$, even if there actually are some alternatives. After all, the CoP is more permissive than the CoJ. Second, as Dawid (2013: 91-2) rightly notes, it does not seem that loop quantum gravity should be considered an actual alternative to string theory because only the latter of the two approaches attempts a full unification of all the fundamental physical forces. Of course, the proponent of loop quantum gravity might not think unifying all the fundamental forces is a particularly pressing problem, but as discussed earlier, unification has been an important, and perhaps a constitutive goal, of fundamental physics, since its inception. At the very least, insofar as a theory $\mathrm{T}$ leads to a greater unification of the phenomena than some rival $\mathrm{T}^{*}$, then, other things being equal, $\mathrm{T}$ seems preferable to $\mathrm{T}^{*}$. While there are, of course, other considerations besides unification that go into evaluating a scientific theory, the opponent of a rival to string theory should be wary of abandoning the goal of unification.

${ }^{30}$ See also Woit (2006: 224).
} 
moment for explaining $\mathrm{P}$, seems eminently sensible. ${ }^{31}$ Further inquiry into $\mathrm{T}$ either might resolve its empirical and conceptual problems or point the way toward an alternate solution.

Likewise, the meta-inductive argument (MIA) might similarly be recast in the CoP. An argument that moves from the premise that theory $T_{1}$ possesses characteristics $c_{1}, c_{2}, \ldots, c_{n}$ in common with successful theories $T_{2}, \ldots, T_{n}$ to the conclusion that $T_{1}$, will, likewise, turn out to be successful, seems, even in the best case, to be of limited epistemic import. Even if the MIA can be given a rigorous formalization within the Bayesian framework, which remains an open question (Dawid et al. 2015: 225), it is doubtful that such an argument could be used to justify full-fledged belief in a theory.

Even so, like the NAA, such an argument appears more suited to the CoP. The MIA can easily be reformulated as an argument by analogy, which brings to the fore its potential relevance in the CoP. We might say that string theory is analogous in many respects to other theories in high-energy physics that have turned out to be successful. As several philosophers have observed (Whitt 1992: 624; Schaffner 1993: 52; Nyrup 2014), arguments by analogy are a common way that scientists advance a hypothesis as worthy of pursuit, e.g. Rutherford's solar system model of the atom, Dalton's “billiardball" model of gases, Darwinian models of cultural evolution, etc. Ultimately, the reason that anal ogies are relevant in the CoP will depend on a specific account of theory-pursuit. But some reasons include: providing increased understanding (Thagard 1988: 94), facilitating the deduction of predictions in an unfamiliar domain (Whitt 1992: 623), reducing the expected costs associated with a new research program (Nyrup 2014: 10), or providing a modest degree of epistemic support (Bartha 2010: 15-6).

Finally, Dawid's third non-empirical argument, the argument of unexpected explanatory coherence (UEA), is most amenable to being reformulated as an argument for pursuit-worthiness. Proponents of string theory have regarded as highly significant its potential as a deep and all-

\footnotetext{
${ }^{31}$ Lakatos admits this point when he writes, "one may rationally stick to a degenerating programme until it is overtaken by a rival and even after" (1978: 117). So, even if a theory is degenerative by failing to make novel predictions, if it is the only game in town, then it may be rational to pursue that theory.
} 
encompassing explanation. For instance, Greene remarks: “All properties of the microworld are within the realm of its explanatory power" (1999: 143). What Dawid (2103: 33-5) finds particularly salient about string theory, however, is that the collection of facts that are brought together under its explanatory umbrella are surprising or unexpected. For example, string theory is not only able to accommodate gravity, but also surprisingly implies the existence of the graviton, the hypothetical force-carrying particle that mediates the gravitational force; moreover, string theory provides an explanation of the laws governing blackhole entropy, as well as rendering coherent other seemingly unrelated phenomena. To be sure, Dawid (2013: 34-5) is wary of employing IBE here to move from the surprising explanatory coherence afforded by string theory to the conclusion that string theory is true, as there may be unconceived alternatives that provide the same degree of explanatory coherence and yet do not entail string theory.

Nevertheless, the alleged explanatory coherence afforded by string theory, if it obtains, might provide a powerful argument for string theory's being highly worthy of pursuit. ${ }^{32}$ An idea that is being increasingly explored by philosophers is that IBE is more suitably employed in the CoP, rather than in the CoJ. On this novel approach to IBE, explanatory reasoning partly determines which hypotheses are worthy of pursuit, or worthy of acceptance in the sense defined in section $5 .{ }^{33}$ Although a full defense of the idea that explanation guides theory-pursuit cannot be offered here, there are several powerful considerations in favor of this alternative view of IBE.

For one thing, consider that while truth is plausibly a goal of science, truth cannot be its only goal. ${ }^{34}$ It is a mistake to think that scientists only care about high probabilities because a hypothesis

\footnotetext{
${ }^{32} \mathrm{It}$ is worth mentioning that some critics of string theory, including Smolin (2006), doubt that string theory actually does have such explanatory power. I will stay neutral on this point. Here, I will agree with Dawid (2013: 22, fn. 19) "that we ought to ignore Smolin's internal string theoretical assessments and stick to those arguments which drive the debate at a more general level."

33 See, for instance, McKaughan (2008), Dawes (2013), Nyrup (2015), Cabrera (2017), and Jones (2018).

${ }^{34}$ Of course, the anti-realist would dispute this commonly endorsed claim, maintaining that the goal of science is not truth or explanatory content, but rather empirical adequacy. But even the anti-realist should be able to accept most of
} 
can be very highly probable by saying hardly anything about the world. For instance, a hypothesis according to which opium puts people to sleep because it has the "dormitive virtue" — thereby positing an unspecified dispositional property to account for opium's soporific powers — will have a probability of unity or near unity. Of course, such vacuous hypotheses are not at all worthy of pursuit, or worthy of commitment, since such views say little about the world. This shows that high probability is not the only goal of science. As a solution to this problem, Popper posits that science has another goal in addition to truth, namely "high informative content" (1959: 399). Now, it is true that scientists do prefer theories with high informative content, but it is not just any kind of content, since information comes cheap. One can trivially increase informative content by artificially logically strengthening one’s hypothesis, e.g. by tacking on an irrelevant conjunct. Instead, it is better to say that scientists care about, in addition to theories with a high probability, theories with a high degree of explanatory content. ${ }^{35}$ The explanatory content of a hypothesis is plausibly determined by well-known explanatory virtues, such as scope, precision, generality, consilience, unification, simplicity, etc.

Furthermore, there is a strong reason to think that some of these explanatory virtues, such as scope cannot, in principle, be accounted for in the CoJ. ${ }^{36}$ The reason for this is that a theory $\mathrm{T}$ with great scope will be logically stronger than some conjunction of its logical consequences $\mathrm{C}_{1} \& \mathrm{C}_{2}$ with less scope, and thus, according to a theorem of the probability calculus, necessarily, $\operatorname{Pr}(\mathrm{T}) \leq \operatorname{Pr}\left(\mathrm{C}_{1} \& \mathrm{C}_{2}\right)$.

\footnotetext{
the analysis I've offered here, for even the anti-realist should admit a distinction between the CoJ and the CoP. Presumably, for the anti-realist, the CoP involves judgments that a theory $\mathrm{T}$ is potentially empirically adequate (and satisfies other practical constraints), whereas the CoJ involves judgements that $\mathrm{T}$ is actually empirically adequate. Thus, not unlike the realist who can regard a theory $\mathrm{T}$ as worthy of pursuit, even though $\mathrm{T}$ is false, for the anti-realist, $\mathrm{T}$ might be worthy of pursuit, even if $\mathrm{T}$ is not now known to be empirically adequate. Perhaps if $\mathrm{T}$ is suitably modified, $\mathrm{T}$ will be found to be empirically adequate, or perhaps experiments testing T's adequacy were inconclusive, or perhaps further work on $\mathrm{T}$ will lead to a better theory $\mathrm{T}^{*}$ that is empirically adequate. Since the anti-realist has the conceptual space for the distinction between the CoP and the CoJ, endorsing anti-realism is not incompatible with endorsing the Conflation Thesis. Even if anti-realism is true, it will still be the case that parties in the string theory debates regularly conflate, or at least do not clearly respect, the distinction between the CoP and CoJ, which is a key source of confusion.

${ }^{35}$ In support of this idea, it is frequently claimed by philosophers and scientists alike that one of the goals of science is explanation. See, for instance, McCain (2016: 133), Strevens (2006: 518), and Wetzstein (2013: 16).

${ }^{36} \mathrm{Granted}$, there are attempts to show that some of these virtues, if understood in a specific way, are relevant in the CoJ. See, for instance, Bayesian explications of simplicity (Dowe et al. 2007) and of unification (Myrvold 2017).
} 
To fix ideas, imagine that $\mathrm{T}=$ Newton's theory of gravity and $\mathrm{C}_{1} \& \mathrm{C}_{2}=$ Galileo's law of falling bodies \& Kepler's three laws of planetary motion. It is traditionally held that Newton's theory is scientifically preferable to the mere conjunction of Galileo's law and Kepler's laws because of its greater scope in accounting for phenomena in other domains (Salmon 1990). However, Newton's theory entails the conjunction of Galileo's law and Kepler's laws, and so, by mathematical necessity, the probability of Newton's theory cannot be greater than the probability of the mere conjunction. Thus, scope cannot be preferable on the basis of its being truth-indicative. It is owing to an argument along these lines that Laudan (2004: 18) concludes that we can have a "perfectly general proof that these attributes cannot be epistemic indicators." Because many of these virtues involve an increase in explanatory content, they are extremely difficult to account for in the CoJ. ${ }^{37}$

However, these explanatory virtues, such as scope and precision, seem precisely like the sorts of considerations that partly determine whether a hypothesis is worthy of pursuit. The lack of such virtues explains why dormitive-virtue-esque hypotheses are not worth taking seriously, despite their high probability. In certain contexts, because explanatory content is a goal of science, theories that lack these explanatory virtues will not be worth pursuing.

With this idea in mind, we are in a position to offer a different understanding of the UEA and similar appeals to the alleged explanatory power of string theory. With some ingenuity such appeals to explanatory power could be shown to raise the probability of string theory. But the better interpretation of the frequent invocation of factors such as coherence, unification, and scope in order to defend string theory, is that these are properties that increase the pursuit-worthiness of the theory. And they increase the pursuit-worthiness of the theory precisely because attaining theories with a high

\footnotetext{
${ }^{37}$ Owing to considerations such as these, I argue in Cabrera (2017) that IBE cannot, in principle, be reconciled with Bayesian confirmation theory.
} 
degree of explanatory content is a goal of scientific inquiry. Once again, one of the key arguments extracted and analyzed by Dawid is more profitably located in the CoP rather than the CoJ. ${ }^{38}$

Throughout this discussion, I've pointed out some properties that are plausibly relevant to pursuit-worthiness, at least in some contexts, and suggested that these properties are ones that string theory is alleged to possess. Now, of course, one might despair of ever coming up with a general account of theory-pursuit. Instead, one might think as Schindler (2014: 494) does that "[i]n theory pursuit, as long as one remains consistent, and as long as one doesn't counteract one's other goals by pursuing a theory (and as long as one acts ethically), anything seems to be permissible." We've seen reason to doubt the consistency criterion, but the crucial point is that one might think that there really cannot be an account of theory-pursuit because such judgements are based merely on personal "hunches". If judgements of pursuit-worthiness are made in this way, then one might think that the CoP cannot be rationally reconstructed. Importantly though, even if it is true that there can be no rational reconstruction of the $\mathrm{CoP}$, this won't undermine the explanatory power of the Conflation Thesis; for, it would remain true even then that both sides of the string theory debate do not respect the distinction between epistemic justification and pursuit-worthiness. If there can be no accounting for the CoP, then we can still explain the protracted controversy concerning string theory as a fruitless debate over a question that cannot, in principle, be rationally adjudicated.

It is doubtful, however, that the $\mathrm{CoP}$ is entirely incapable of rational reconstruction, since these judgements, at least some of the time, appear to have a "rich, internal structure" (French 1995: 93). Typically, hunches have some underlying rationale, which may not be immediately evident, but

\footnotetext{
38 Similarly, Rickles offers another sort of non-empirical argument for string theory, relying on the extraordinary claim that "if a physical theory enables one to make strides in mathematics, and come up with interesting, highly applicable results, then this ought to cause up [sic] to up our degree of belief in the theory" (2013: 72). String theory has led to interesting mathematics, but is that any reason to believe the theory correctly describes physical reality? What motivates Rickles here is better accounted for by thinking in terms of pursuit-worthiness instead of belief-worthiness. The fact that string theory has led to interesting mathematics may be good reason to continue to pursue the theory.
} 
which remains discoverable upon reflection. It is not normally the case that a scientist thinks a theory is promising for absolutely no reason whatsoever. Now, what might be true about the CoP is that whether a hypothesis is worthy of pursuit depends on the specific aim of inquiry, in which case pursuitworthiness should be relativized to a determinate research context. On this view, pursuit-worthiness would amount to a three-place relation between a theory $\mathrm{T}$, a set of phenomena $\mathrm{P}$, and a context of inquiry C. It would be a mistake though to claim that the contextualist character of theory-pursuit entails that there cannot be any accounting of pursuit at all. ${ }^{39}$

\section{Concluding Remarks}

In this paper, I have considered what best explains the heated and seemingly intractable controversies in fundamental physics regarding the status of string theory. As Dawid has argued, the best explanation of the disagreement is that there has been a quiet revolution in what is to count as good scientific methodology. On Dawid's view, string theorists have unintentionally widened the canons of scientific inference to include what he calls "non-empirical theory assessment". Thus, Dawid's explanation of the controversy is that a methodological revolution with respect to admissible inferential strategies in science is occurring, which is not being openly debated.

Against this explanation, I have offered an alternative one. On my view, the best explanation for the polarized reactions to string theory is that parties on both sides of the debate have not properly distinguished the "context of justification"-which concerns questions about knowledge, epistemic justification, and evidential support—from the "context of pursuit"—which concerns primarily the question of whether a theory or research program is promising or worthy of pursuit. As I have

\footnotetext{
${ }^{39}$ Indeed, there is good reason to think that a proper account of the CoJ will likewise turn out to have a contextualist character. As Sober points out, the Bayesian framework makes sense only if the goal of inference is truth, but when the goal of the research context is predictive accuracy, one is better off appealing to some model selection criteria, such as the "Akaike Information Criterion" (see Forster and Sober (1994) for further discussion of AIC). As Sober aptly observes, "[w] hen predictive accuracy is substituted for truth as the goal of inference, the epistemological landscape undergoes a fundamental change" (2002: 36). It would appear then that the CoP and the CoJ are in the same boat.
} 
attempted to show, this distinction between the $\mathrm{CoJ}$ and the $\mathrm{CoP}$ is not clearly respected by influential opponents and proponents of string theory, including Dawid, and in some cases the distinction is blatantly conflated. This conflation of the CoP and the CoJ, along with the fact that there is no widely accepted account of theory-pursuit, is the better explanation of the controversy. If my analysis is correct, then one way to ameliorate the controversy over string theory is to make clear the distinction between the CoJ and the CoP, and further investigate the norms that govern the CoP.

Additionally, as I have shown, the sorts of arguments in favor of string theory that Dawid has extracted and analyzed make better sense if construed as reasons to pursue, and not reasons to believe, string theory. Insofar as the view that I defend here is acceptable to critics of string theory-i.e. that the arguments presented by Dawid are reasons to pursue the theory but not reasons to believe the theory — then it should be regarded as a clarification of their position (e.g. Rovelli 2016). While I have not attempted to articulate a full-fledged account of theory-pursuit, as I've suggested, explanatory virtues such as scope, unification, etc. are relevant to theory-pursuit, at least in the context of fundamental physics. To be sure, I have not attempted to fully defend the claim that string theory is worthy of pursuit because it possesses these virtues. Doing so would require a more in-depth study at the first-order level of whether the theory actually has the explanatory virtues that are commonly attributed to it—something which opponents of the theory sometimes doubt. Nevertheless, if the theory does have these virtues, and if indeed there are no extant theories to rival its alleged explanatory power, then this set of facts does amount to an argument in favor of pursuing string theory. On my analysis, we can accept that string theory is worthy of pursuit, without thinking that these arguments provide us sufficient reason to think that the theory is true. Thus, contra Dawid, we are not compelled to think that fundamental physics has provoked a revolution in scientific method. 


\section{References}

Achinstein, P. (1993). "How to defend a theory without testing it: Niels Bohr and the logic of pursuit,", Midwest Studies in Philosophy, 13: 90-120.

Audi, R. (2008). “Belief, Faith, and Acceptance," International Journal for Philosophy of Religion, 63: 87102.

Bartha, P. (2010). By Parallel Reasoning: The Construction and Evaluation of Analogical Arguments. New York: Oxford University Press.

Batterman, R. (2009). "Idealization and modeling," Synthese 169, 427-46.

Biggs, S. and Wilson, J. (2017). “The A Priority of Abduction,” Philosophical Studies, 174(3): 735-58.

Bird, A. (2010). "Eliminative Abduction: Examples from Medicine," Studies in History and Philosophy of Science Part A, 41(4): 345-52.

Bokulich, A. (2011). “How Scientific Models Can Explain,” Synthese, 180 (1): 33-45.

Bonjour, L. (1985). The Structure of Empirical Knowledge. Cambridge, MA: Harvard University Press.

Braithwaite, R. (1953). Scientific Explanation. Cambridge: Cambridge University Press.

Bratman, M. (1999). Faces of Intention. Cambridge: Cambridge University Press

Briggs, W. (2016). Uncertainty: The Soul of Modeling, Probability \& Statistics. Switzerland: Springer International Publishing.

Cabrera, F. (2017). "Can there be a Bayesian Explanationism?: On the Prospects of a Productive Partnership," Synthese, 194(4): 1245-72.

Camilleri, K. and Ritson, S. (2015). "The Role of Heuristic Appraisal in Conflicting Assessments of String Theory," Studies in History and Philosophy of Science Part B: Studies in History and Philosophy of Modern Physics, 51: 44-56.

Carnap, R. (1950). Logical Foundations of Probability. Chicago: University of Chicago Press.

Cartwright, N. and Frigg, R. (2007). "String Theory Under Scrutiny," Physics World 20, 14-15.

Cohen, J. (1992). An Essay on Belief and Acceptance. New York: Oxford University Press

Conee, E., \& Feldman, R. (2004). Evidentialism: Essays in Epistemology. Oxford University Press.

Darden, L. (1991). Theory Change in Science: Strategies from Mendelian Genetics. Oxford: Oxford University Press.

Dawes, G. (2013). "Belief is Not the Issue: A Defence of Inference to the Best Explanation," Ratio, 26(1):62-78.

Dawid, R. (2013). String Theory and the Scientific Method. Cambridge: Cambridge University Press. 
Dawid, R. (2016). “Modelling Non-empirical Confirmation”, in E. Ippoliti, F. Sterpetti, T. Nickles (eds.), Models and Inferences in Science. Switzerland: Springer International Publishing, 191-205.

Dawid, R., Hartmann, S. and Sprenger, J. (2015). “The No Alternatives Argument,” Brit. J. Phil. Sci. 66 (1): 213-34.

De Finetti, B. (1974). Theory of Probability. New York: John Wiley and Sons.

Dowe, D., Gardner, S. and Oppy, G. (2007). "Bayes not bust! Why simplicity is no problem for Bayesians," Br. J. Philos. Sci., 58: 709-754.

Duff, M. (2013). "String and M-theory: Answering the critics," Foundations of Physics, 43(1): 182-200.

Elgin. C. (2007). "Understanding and the Facts", Philosophical Studies, 132: 33-42.

Elliott, K.C. and Willmes, D. (2013). "Cognitive Attitudes and Values in Science," Philosophy of Science, 80(5): 807-817.

Ellis, G. and Silk, J. (2014). "Scientific method: Defend the integrity of physics," Nature 516: 321-23.

Foley, R. (1992). “The Epistemology of Belief and the Epistemology of Degrees of Belief”, American Philosophical Quarterly, 29(2): 111-21.

Forster, M. and Sober, E. (1994). "How to Tell When Simpler, More Unified, or Less Ad Hoc Theories will Provide More Accurate Predictions," Brit. J. Phil. Sci., 45(1): 1-35.

Franklin, A. and E. Fischbach. (2016). The Rise and Fall of the Fifth Force: Discovery, Pursuit, and Justification in Modern Physics. Switzerland: Springer International Publishing.

French, S. (1995). "The Esperable Uberty of Quantum Chromodynamics”, Stud. His. Phil. Mod. Phys., 26(1): 87-105.

Frost-Arnold, K. (2014). “The Cognitive Attitude of Rational Trust,” 191(9): 1957-74.

Green, M. and Schwarz, J. (1984). “Anomaly Cancellations in Supersymmetric D = 10 Gauge Theory and Superstring Theory," Physics Letters B 149: 117-22.

Greene, B. 1999. The Elegant Universe: Superstrings, hidden dimensions, and the quest for the ultimate theory. New York: W. W. Norton.

Hanson, N. (1958). Patterns of Discovery: An Inquiry into the Conceptual Foundations of Science. Cambridge, MA: Harvard University Press.

Hawley, K. (2006). "Science as a Guide to Metaphysics?”, Synthese, 149: 451-70.

Hempel, C. (1965). Aspects of Scientific Explanation. New York: Free Press.

Henderson, L. (2014). "Bayesianism and Inference to the Best Explanation," Brit. J. Phil. Sci., 65(4): 687-715. 
Herzberg, F. (2014). “A Note on 'The No Alternatives Argument' by Richard Dawid, Stephan Hartmann and Jan Sprenger," European Journal for Philosophy of Science, 4(3): 375-84.

Howson, C. and Urbach, P. (2006). Scientific Reasoning: The Bayesian Approach. Peru, IL: Open Court. Isham, C.J. (1981). "Quantum Gravity - An Overview”, in C.J. Isham, R. Penrose and D.W. Sciama (eds.), Quantum Gravity 2: A Second Oxford Symposium. Oxford: Oxford University Press, 1-62.

Jantzen, B. (2016). "Discovery without a 'logic' would be a miracle," Synthese, 193(10): 3209-38.

Johnson, C. (2006). "Asymptotia: More scenes for a storm in a Teacup VI" < http://asymptotia. com/2006/11/10/more-scenes-from-the-storm-in-a-teacup-vi/>

Jones, N. (2018). "Inference to the More Robust Explanation,” Brit. J. Phil. Sci. 69(1): 75-102.

Jones, T. (2008). "Unification." in S. Psillos and M. Curd (eds.), The Routledge Companion to Philosophy of Science. London: Routledge, 489-497.

Kachru, S., Kalloch, R., Linde, A., \& Trivedi, S.P. (2003). “De Sitter vacua in string theory,” Physical Review, D 68: 046005.

Kitcher, P. (1993). The Advancement of Science: Science Without Legend, Objectivity Without Illusions. Oxford University Press.

Kuhn, T. (1962). The Structure of Scientific Revolutions, $1^{\text {st }}$ ed. Chicago: University of Chicago Press.

Kyburg, H. (1961). Probability and the Logic of Rational Belief. Middletown: Wesleyan University Press.

Lakatos (1978). The Methodology of Scientific Research Programmes. Cambridge University Press.

Laudan, L. (1977). Progress and its Problems: Toward a Theory of Scientific Growth. Berkeley, CA: University of California Press.

Laudan, L. (1984). Science and V alues: The Aims of Science and Their Role in Scientific Debate. Berkeley, CA: University of California Press.

Laudan, L. (2004). “The Epistemic, the Cognitive, and the Social," in P. Machamer, and G. Wolters (eds.), Science, Values, and Objectivity. Pittsburgh: University of Pittsburgh Press, 14-23.

Lipton, P. (2004). Inference to the Best Explanation, $2^{\text {nd }}$ ed. New York: Routledge.

Maddy, P. (1992). "Indispensability and Practice," Journal of Philosophy, 89(6): 275-89.

McCain, K. (2014). Evidentialism and Epistemic Justification. Routledge.

McCain, K. (2016). The Nature of Scientific Knowledge: An Explanatory Approach. Switzerland: Springer International Publishing.

McKaughan, D. (2008). "From Ugly Duckling to Swan: C. S. Peirce, Abduction, and the Pursuit of Scientific Theories," Transactions of Charles S. Peirce Society, 4(3): 446-68.

Mill, J.S. (1843). A System of Logic, Ratiocinative and Inductive. London: John W. Parker. 
Morganti, M. and Tahko, T. (2016). “Moderately Naturalistic Metaphysics," Synthese 194 (7):2557-80.

Musgrave, A. (1974). "Logical Versus Historical Theories of Confirmation,” Brit. J. Phil. Sci., 25(1): $1-23$.

Myrvold, W. (2017). “On the Evidential Import of Unification”, Philosophy of Science, 84(1): 92-114.

Nickles, T. (2006). "Heuristic appraisal: Context of discovery or justification?” in J. Schickore and F. Steinle (eds.), 159-182.

Nolan, D. (2015). “The A Posteriori Armchair,” Australasian Journal of Philosophy, 93(2), 211-31.

Nyrup, R. (2014). “Analogy and Pursuitworthiness," Unpublished MS, < http://philsciarchive.pitt.edu/10987/1/Analogy_\%26_Pursuitworthiness\%2C_BSPS_Paper.pdf>

Nyrup, R. (2015). “How Explanatory Reasoning Justifies Pursuit: A Peircean View of IBE,” Philosophy of Science, 82: 749-60.

Pickering, A. (1984). Constructing Quarks: A Sociological History of Particle Physics. University of Chicago Press.

Platt, J. (1964). “Strong Inference," Science, 146: 347-53.

Polchinski, J. (2016). "Why trust a theory? Some further remarks (part 1)" arXiv:1601.06145 [hep-th]. Pojman, L.P. (1999). "Believing, Willing, and the Ethics of Belief," in The Theory of Knowledge, 2nd ed. Belmont, CA: Wadsworth.

Popper, K. (1959). The Logic of Scientific Discovery. London: Routledge.

Potochnik, A. (2017). Idealization and the Aims of Science. Chicago: University of Chicago Press.

Psillos, S. (2002). "Simply the Best: A Case for Abduction," in A. C. Kakas and F. Sadri (eds.), Computational Logic: Logic Programming and Beyond. Berlin: Springer-Verlag, 605-26.

Reichenbach, H. (1938). Experience and Prediction. Chicago: University of Chicago Press.

Reichenbach, H. (1958). The Rise of Scientific Philosophy. Berkeley: University of California Press.

Rickles, D. (2013). "Mirror Symmetry and Other Miracles in Superstring Theory," Foundations of Physics, 43: $54-80$.

Rickles, D. (2014). A Brief History of String Theory: From Dual Models to M-Theory. Berlin: Springer.

Rovelli, C. (2005). “A Theory of Everything?” Nature, 433 (7023): 257-259.

Rovelli, C. (2016). “The Dangers of Non-Empirical Confirmation”, arXiv:1609.01966.

Salmon, W. (1970). "Bayes's Theorem and the History of Science”, in R. H. Stuewer (ed.), Historical and Philosophical Perspectives of Science (Minnesota Studies in the Philosophy of Science Vol. 5). Minneapolis: University of Minnesota Press, 68-86. 
Salmon, W. (1990). "Rationality and Objectivity in Science or Tom Kuhn Meets Tom Bayes," In C. Wade Savage (ed.), Scientific Theories, vol. 14. Minneapolis: University of Minnesota Press, 175204.

Schaffner, K. F. (1974). "Logic of Discovery and Justification in Regulatory Genetics," Studies in History and Philosophy of Science 4: 349-85.

Schickore, J. and Steinle, F. (2006). Revisiting Discovery and Justification: Historical and Philosophical Perspectives on the Context Distinction. Dordrecht: Springer.

Schindler, S. (2014). "A Matter of Kuhnian Theory-Choice?: The GWS Model and the Neutral Current," Perspectives on Science, 22 (4): 491-522.

Scott-Kakures, D. (2000). "Motivated Believing: Wishful and Unwelcome," Nous, 34: 348-75.

Šešelja, D. and Straßer, C. (2014). "Epistemic justification in the context of pursuit: a coherentist approach," Synthese, 191: 3111-41.

Smolin, L. (2006). The Trouble with Physics. Boston, MA: Houghton Mifflin.

Smolin, L. (2013). "A Perspective on the Landscape Problem," Foundations of Physics, 43: 21-45.

Sober, E. (1990): "Contrastive Empiricism," in W. Savage (ed.), Minnesota Studies in the Philosophy of Science: Scientific Theories, 14. Minneapolis, MN: University of Minnesota Pres, 392-412.

Sober, E. (2002). "Bayesianism-Its Scope and Limits" in R. Swinburne, (ed.), Bayes' Theorem, Proceedings of the British Academy Press, 113: 21-38.

Strevens, M. (2006). "Explanation," in D.M. Borchert (ed.), Encyclopedia of Philosophy, 2nd ed. Detroit: Macmillan, 518-27

Susskind, L. (2013). "String Theory," Foundations of Physics, 43: 174-81.

Thagard, P. (1988). Computational Philosophy of Science. Cambridge, MA.: MIT Press.

van Fraassen, B.C. (1980). The Scientific Image. Oxford: Oxford University Press.

Veneziano, G. (1968). "Construction of a crossing-symmetric, regge-behaved amplitude for linearly rising trajectories", Nuovo Cimento A, 57:190-197.

Vickers, P. (2013). Understanding Inconsistent Science. Oxford University Press.

Wetzstein, M. (2013). Microeconomic Theory Second Edition: Concepts and Connections. New York, NY: Routledge.

Whewell, W. (1840). The Philosophy of the Inductive Sciences. London: John W. Parker.

Whitt, L.A. (1990). “Theory Pursuit: Between Discovery and Acceptance," PSA: Proceedings of the Biennial Meeting of the Philosophy of Science Association, Vol. 1990, Volume One: Contributed Papers, 467-483. 
Whitt, L.A. (1992). "Indices of Theory Promise," Philosophy of Science, 59(4): 612-634.

Williams, B. (1970). “Deciding to Believe," in H.E. Kiefer and M.K. Munitz (eds.), Language, Belief, and Metaphysics. Albany: SUNY Press, 95-111.

Williamson, T. (2016). “Abductive Philosophy," The Philosophical Forum, 47: 263-80.

Witten, E. (1995) "String theory dynamics in various dimensions," hep-th/9503124, Nuclear Physics B443, 85-126.

Witten, E. (2005). “Unravelling String Theory,” Nature, 438, 1085

Woit, P. (2006). Not Even Wrong: The Failure of String Theory and the Continuing Challenge to Unify the Laws of Physics. London: Vintage Books. 